\title{
Desempenho produtivo, composição corporal e parâmetros fisiológicos de pacu alimentado com níveis crescentes de fibra
}

\author{
Laurindo André Rodrigues ${ }^{(1)}$, João Batista Kochenborger Fernandes ${ }^{(2)}$, Thiago El Hadi Perez Fabregat(3) \\ e Nilva Kazue Sakomura(4) \\ (1)Embrapa Meio-Norte, Unidade de Execução de Pesquisa de Parnaíba, Caixa Postal 341, CEP $64200-970$ Parnaíba, PI. \\ E-mail: laurindo@cpamn.embrapa.br (2)Universidade Estadual Paulista Júlio de Mesquita Filho (Unesp), Centro de Aquicultura, Via de Acesso \\ Prof. Paulo Donato Castelane, s/no CEP 14884-900 Jaboticabal, SP. E-mail: jbatista@caunesp.unesp.br (3)Unesp, Instituto de Biociência, \\ Distrito de Rubião Junior, s/no CEP 18618-970 Botucatu, SP. E-mail: thiagofabregat@hotmail.com (4)Unesp, Faculdade de Ciências \\ Agrárias e Veterinárias, Departamento de Zootecnia, Via de Acesso Prof. Paulo Donato Castelane, s/no CEP 14884-900 Jaboticabal, SP. \\ E-mail: sakomura@fcav.unesp.br
}

Resumo - O objetivo deste trabalho foi avaliar os efeitos de teores de fibra bruta na dieta sobre o desempenho produtivo, composição centesimal da carcaça e parâmetros fisiológicos de juvenis de pacu. O experimento

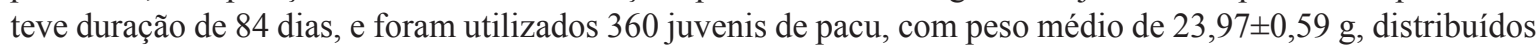
aleatóriamente em 30 tanques com $180 \mathrm{~L}$ de água, em delineamento inteiramente casualizado, com seis tratamentos $(5,7,9,11,13$ e $15 \%$ de fibra bruta) e cinco repetições. Dietas com altos teores de fibra $(11,13$ e 15\%) resultaram em piores taxas de ganho de peso, conversão alimentar e crescimento específico, além de menor eficiência proteica e consumo de ração. A composição da carcaça dos animais foi alterada pelo aumento do teor de fibra das dietas. Os teores de proteína e cinza tiveram aumento com o incremento nos teores de fibra. O metabolismo foi alterado com o emprego de teores crescentes de fibra, o que resultou em pequena elevação do colesterol plasmático. Teores de fibra bruta de até $9 \%$ não tiveram efeitos negativos no metabolismo; entretanto, teores acima de $11 \%$ reduziram o crescimento dos peixes.

Termos para indexação: Piaractus mesopotamicus, alimentação, metabolismo, nutrição.

\section{Productive performance, body composition and physiological parameters of pacu fed increasing levels of fiber}

\begin{abstract}
The objective of this work was to evaluate the effects of dietary crude fiber contents on productive performance, carcass composition and physiological parameters of pacu juveniles. The experiment was carried out during 84 days, 360 pacu juveniles were used with mean weight $23.97 \pm 0.59 \mathrm{~g}$, stocked in 30 tanks with $180 \mathrm{~L}$ of water, in a completely randomized design, with six treatments $(5,7,9,11,13$ and $15 \%$ crude fiber) and five replicates. Diets with high fiber contents (11, 13 and 15\%) resulted in worse rates of weight gain, feed conversion, and specific growth, besides lower protein efficiency ratio and feed consumption. Carcass composition changed by increasing the contents of dietary fiber. Body contents of protein and ash increased along with the fiber levels. The metabolism changed with the use of increasing levels of fiber, which resulted in a slight elevation of serum cholesterol. Crude fiber content up to $9 \%$ had no negative effects on metabolism, but levels above $11 \%$ reduced fish growth.
\end{abstract}

Index terms: Piaractus mesopotamicus, feeding, metabolism, nutrition.

\section{Introdução}

A fibra alimentar é composta por polissacarídeos não digeríveis pelas enzimas digestivas de animais monogástricos, e pode proporcionar benefícios à saúde animal (Knudsen, 2001; Montagne et al., 2003). A fibra pode produzir efeitos fisiológicos variados, a depender de sua natureza química e de sua estrutura física - tamanho da partícula, peso molecular e grau de esterificação (Bijlani, 1985).

Os efeitos da fibra na digestão do alimento e absorção dos nutrientes são altamente influenciados por suas propriedades físicas e químicas (Wenk, 2001). A fibra dietética é a parte estrutural das plantas e é resistente à hidrólise pelas enzimas do intestino delgado (Thebaudin et al., 1997). A fibra é formada por celulose, hemicelulose e substâncias pécticas (Hilton at al., 1983), que variam bastante seus conteúdos de acordo com a espécie e idade da planta (Andriguetto, 2002). A composição da fibra altera seu efeito na digestão e absorção dos nutrientes da dieta (Montagne et al., 2003).

Dioundick e Stom (1990) demonstraram, em experimento com tilápia-do-nilo (Oreochromis

Pesq. agropec. bras., Brasília, v.45, n.8, p.897-902, ago. 2010 
niloticus), que os melhores resultados para crescimento, conversão alimentar e taxa de eficiência proteica foram apresentados por animais alimentados com dietas que continham 2,5 e $5 \%$ de fibra bruta, em comparação a níveis mais elevados (7,5 e 10\%). Em trabalho com matrinxã (Brycon cephalus), Pereira-Filho et al. (1994) observaram que 2, 10 e $20 \%$ de fibra bruta na dieta não provocaram alteração no ganho de peso, mas melhoraram a qualidade da carcaça ao elevar os teores corporais de proteína e cinzas e reduzir os de gordura. Garcia (1998) testou a utilização de 5 a $9 \%$ de fibra bruta na nutrição da piracanjuba (Brycon orbignyanus) e demonstrou que a melhor resposta de ganho de peso foi obtida com a dieta com $9 \%$ de fibra bruta.

O pacu, é uma espécie muito cultivada no Brasil, possui ampla distribuição geográfica e pode ser encontrado desde a Bacia dos Rios Paraná-Paraguai até a Bacia do Rio Prata. É um peixe que altera sua alimentação de acordo com a sazonalidade da disponibilidade de alimentos. Segundo Urbinati \& Gonçalvez (2005), a alimentação do pacu é baseada em folhas, resíduos vegetais e, raramente, peixes e moluscos. Esses autores constataram que o pacu é uma espécie herbívora que tolera níveis elevados de fibra na dieta.

Para melhorar e maximizar a utilização dos alimentos pelo pacu, é necessário conhecer os efeitos de níveis de fibra no aproveitamento da dieta. Estudos sobre o desempenho produtivo de peixes, alimentados com fibras, e os efeitos fisiológicos da inclusão da fibra em dietas podem resultar em maior precisão no balanceamento da dieta e possibilitar o aproveitamento de ingredientes fibrosos.

O objetivo deste trabalho foi avaliar os efeitos de teores de fibra bruta na dieta sobre o desempenho produtivo, composição centesimal da carcaça e parâmetros fisiológicos de juvenis de pacu.

\section{Material e Métodos}

O experimento foi desenvolvido no Laboratório de Peixes Ornamentais, do Centro de Aquicultura da Universidade Estadual Paulista (Unesp), Jaboticabal, SP, de 10 de fevereiro a 5 de maio de 2007. Foram utilizados 360 juvenis de pacu, com peso médio

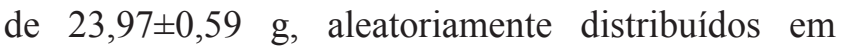
30 tanques com $180 \mathrm{~L}$ de água, na densidade de 12 peixes por tanque.
Durante o experimento, os peixes foram alimentados com as dietas experimentais até a saciedade aparente, duas vezes por dia. Diariamente, as unidades experimentais foram sifonadas para a retirada dos dejetos dos peixes e troca parcial de água, sem fluxo contínuo de água e com aeração. A temperatura dos aquários foi aferida diariamente, com um termômetro de máxima e mínima. $\mathrm{O}$ oxigênio dissolvido e o $\mathrm{pH}$ da água foram monitorados semanalmente, com equipamentos eletrônicos multiparâmetros YSI 556 (YSI Incorporated, Yellow Spring, Ohio, USA), durante todo o período experimental.

Utilizou-se o delineamento experimental inteiramente casualizado, com seis tratamentos e cinco repetições. Os tratamentos foram representados pelas seguintes taxas de inclusão de fibra bruta nas dietas: $5,7,9,11,13$, e 15\%, (Tabela 1). A principal fonte de fibra utilizada foi a celulose microfina Rhoster (Rhoster Indústria e Comércio Ltda., Vargem Grande Paulista, SP, Brasil) com $98 \%$ de pureza e $78 \%$ de fibra bruta. As dietas foram formuladas conforme as necessidades do pacu (Fernandes et al., 2001; Abimorad et al., 2007), e extrusadas na fábrica de ração do Departamento de Produção Animal da Unesp.

Para analisarodesempenho dospeixes, foramavaliados os seguintes parâmetros: ganho de peso (diferença entre peso inicial e final); taxa de crescimento específico $\mathrm{TCE}=[\mathrm{Ln}$ (peso final) - Ln (peso inicial)/número de dias x 100]; consumo de ração, medido pela diferença de peso do recipiente individual de cada unidade experimental; conversão alimentar $(\mathrm{CA}=$ consumo de ração/ganho de peso) e taxa de eficiência proteica $\mathrm{TEP}=$ ganho de peso/(consumo de ração $\mathrm{x}$ percentagem de proteína bruta da dieta) x 100]. Uma amostra de dois peixes por parcela foi separada para a análise de composição centesimal da carcaça, realizada no Laboratório do Setor de Avicultura da FCAV-Unesp. Os peixes foram moídos e secos em estufa a $65^{\circ} \mathrm{C}$, por 72 horas. Após a secagem, os peixes foram novamente moídos em moinho de bola, para as futuras análises. O extrato etéreo foi determinado em aparelho extrator de gordura Soxlet Marconi (Marconi Equipamentos para Laboratório Ltda., Piracicaba, Brasil), a determinação da proteína foi realizada pelo método de Kjeldahl, e a matéria mineral foi determinada em mufla à $600^{\circ} \mathrm{C}$, por 4 horas, conforme Silva \& Queiroz (2006). Para a análise dos parâmetros fisiológicos sanguíneos, um peixe por repetição foi submetido à punção da veia caudal para retirada de sangue. Foram analisados: 
glicemia, colesterol, triglicerideos e proteína total por meio do kit de laboratório (Labtest Diagnóstica, Lagoa Santa, Brasil). Os princípios dos testes são reação de Trinder, para glicemia, colesterol e triglicerideos, e reação de biureto, para proteínas totais.

As análises estatísticas foram realizadas pelo SAS (SAS Institute, 2006). Foram conduzidos os testes de normalidade dos erros e homocedasticidade da variância, e as diferenças foram avaliadas por meio da análise de variância. As médias foram comparadas pelo teste de Duncan a 5\% de probabilidade.

\section{Resultados e Discussão}

A sobrevivência foi total, pois as condições ambientais estavam adequadas às necessidades dos peixes (Urbinati \& Gonçalves, 2005), com temperatura média da água dos aquários experimentais de $28^{\circ} \mathrm{C}$, oxigênio dissolvido de $7,25 \mathrm{mg} \mathrm{L}^{-1}$ e $\mathrm{pH} 7,4$.

Os peixes alimentados com dietas que continham 5,7 e $9 \%$ de fibra bruta apresentaram maior ganho de peso, taxa de crescimento específico (TCE) e consumo de ração, em comparação àqueles que receberam taxas de fibra mais elevadas (Tabela 2). Os decréscimos

Tabela 1. Formulação e composição centesimal calculada das dietas com diferentes níveis de inclusão de fibra bruta para o pacu.

\begin{tabular}{|c|c|c|c|c|c|c|}
\hline Ingredientes (\%) & $5 \%$ de fibra & $7 \%$ de fibra & $9 \%$ de fibra & $11 \%$ de fibra & $13 \%$ de fibra & $15 \%$ de fibra \\
\hline Farelo de soja & 37,7 & 36,0 & 29,1 & 23,2 & 17,6 & 14,6 \\
\hline Soja integral tostada & 5,0 & 7,0 & 12,5 & 17,2 & 20,0 & 22,5 \\
\hline Farinha de peixe & 10,0 & 10,0 & 10,0 & 10,0 & 10,0 & 10,0 \\
\hline Milho & 12,0 & 11,0 & 12,4 & 9,5 & 4,0 & 1,7 \\
\hline Amido de milho & 25,0 & 22,5 & 15,0 & 10,0 & 4,0 & 0,5 \\
\hline Farelo de trigo & 2,0 & 3,0 & 9,7 & 17,9 & 31,4 & 35,8 \\
\hline Óleo de soja & 3,6 & 3,3 & 2,0 & 1,0 & 0,4 & - \\
\hline Suplemento $^{(1)}$ & 1,0 & 1,0 & 1,0 & 1,0 & 1,0 & 1,0 \\
\hline Calcário & 2,0 & 2,0 & 2,0 & 2,0 & 2,0 & 2,0 \\
\hline Celulose & 1,7 & 4,2 & 6,3 & 8,2 & 9,6 & 11,9 \\
\hline Total & 100 & 100 & 100 & 100 & 100 & 100 \\
\hline & \multicolumn{6}{|c|}{ Composição calculada $^{(2)}$} \\
\hline PB (\%) & 25,98 & 26,01 & 26,0 & 25,99 & 25,98 & 25,98 \\
\hline EB $\left(\mathrm{kcal} \mathrm{kg}^{-1}\right)$ & 4.032 & 3.952 & 3.902 & 3.857 & 3.833 & 3.768 \\
\hline $\mathrm{ED}\left(\mathrm{kcal} \mathrm{kg}^{-1}\right)$ & 3.164 & 3.138 & 3.171 & 3.190 & 3.208 & 3.197 \\
\hline $\mathrm{EE}(\%)$ & 6,60 & 6,67 & 6,62 & 6,60 & 6,62 & 6,72 \\
\hline FB $(\%)$ & 5,10 & 7,15 & 9,30 & 11,38 & 13,41 & 15,53 \\
\hline MM (\%) & 5,50 & 5,54 & 5,75 & 6,00 & 6,41 & 6,55 \\
\hline $\mathrm{Ca}(\%)$ & 1,59 & 1,59 & 1,59 & 1,60 & 1,60 & 1,61 \\
\hline P. total $(\%)$ & 0,67 & 0,68 & 0,74 & 0,80 & 0,89 & 0,92 \\
\hline P. útil (\%) & 0,45 & 0,45 & 0,46 & 0,47 & 0,50 & 0,51 \\
\hline
\end{tabular}

(1)Suplemento vitamínico mineral Rovimix: vitamina A 500.000 UI; D3 20.0000 UI; E, 5.000 UI; K3, 1.000 mg; B1, 1.500 mg; B2, 1.500 mg; B6, 1.500 mg; B12, $4.000 \mathrm{mg}$; C, $15.000 \mathrm{mg}$; ácido fólico, $500 \mathrm{mg}$; ácido pantotênico, $4.000 \mathrm{mg}$; BHT, $12,25 \mathrm{~g}$; biotina, $50 \mathrm{mg}$; inositol, $1.000 \mathrm{mg}$; nicotinamida, $7.000 \mathrm{mg}$; colina, $40 \mathrm{~g}$; cobalto, $10 \mathrm{mg}$; cobre, $500 \mathrm{mg}$; ferro, $5.000 \mathrm{mg}$; iodo, $50 \mathrm{mg}$; manganês, $1.500 \mathrm{mg}$; selênio, $10 \mathrm{mg}$; zinco, $5.000 \mathrm{mg}$; veículo qsq, $1.000 \mathrm{~g}$. ${ }^{(2)} \mathrm{PB}$, proteína bruta; $\mathrm{EB}$, energia bruta; $\mathrm{ED}$, energia digestível; EE, extrato etéreo; FB, fibra bruta; $\mathrm{MM}$, matéria mineral.

Tabela 2. Média \pm desvio-padrão de ganho de peso (GP), taxa de crescimento específico (TCE), consumo de ração, conversão alimentar (CA), taxa de eficiência proteica (TEP) de juvenis de pacu, alimentados com taxas crescentes de fibra bruta na $\operatorname{dieta}^{(1)}$.

\begin{tabular}{lccccc}
\hline Fibra bruta $(\%)$ & GP $(\mathrm{g})$ & TCE & Consumo $(\mathrm{g})$ & CA & TEP \\
\hline 5 & $52,32 \pm 9,88 \mathrm{a}$ & $1,36 \pm 0,52 \mathrm{a}$ & $62,46 \pm 9,73 \mathrm{a}$ & $1,20 \pm 0,08 \mathrm{a}$ & $3,20 \pm 0,22 \mathrm{a}$ \\
7 & $52,05 \pm 5,90 \mathrm{a}$ & $1,38 \pm 0,34 \mathrm{a}$ & $62,85 \pm 6,18 \mathrm{a}$ & $1,21 \pm 0,13 \mathrm{ab}$ & $3,18 \pm 0,32 \mathrm{a}$ \\
9 & $50,96 \pm 2,24 \mathrm{a}$ & $1,37 \pm 0,14 \mathrm{a}$ & $63,74 \pm 2,73 \mathrm{a}$ & $1,25 \pm 0,04 \mathrm{ab}$ & $3,07 \pm 0,10 \mathrm{ab}$ \\
11 & $43,36 \pm 4,05 \mathrm{~b}$ & $1,22 \pm 0,21 \mathrm{~b}$ & $54,33 \pm 4,25 \mathrm{~b}$ & $1,25 \pm 0,03 \mathrm{ab}$ & $3,06 \pm 0,08 \mathrm{ab}$ \\
13 & $39,23 \pm 5,95 \mathrm{bc}$ & $1,14 \pm 0,24 \mathrm{bc}$ & $52,30 \pm 6,18 \mathrm{~b}$ & $1,35 \pm 0,16 \mathrm{bc}$ & $2,87 \pm 0,32 \mathrm{bc}$ \\
15 & $34,90 \pm 1,51 \mathrm{c}$ & $1,06 \pm 0,16 \mathrm{c}$ & $49,99 \pm 1,23 \mathrm{~b}$ & $1,43 \pm 0,04 \mathrm{c}$ & $2,68 \pm 0,07 \mathrm{c}$ \\
\hline $\mathrm{CV}(\%)$ & 12,63 & 8,13 & 7,48 & 7,45 & 7,06 \\
\hline
\end{tabular}

${ }^{(1)}$ Médias seguidas de letras iguais, nas colunas, não diferem entre si pelo teste de Duncan, a 5\% de probabilidade. 
de ganho de peso e de TCE, com a inclusão de fibra acima de $11 \%$, podem estar relacionados à redução do consumo de ração, pois a ingestão de fibra proporciona aumento no volume do bolo alimentar (Montagne et al., 2003) como consequência de sua alta capacidade de retenção de água (Thebaudin et al., 1997), o que aumenta a sensação de saciedade dos animais (Hansen \& Storebakken, 2007). No entanto, Hansen \& Storebakken (2007) não observaram decréscimo no crescimento de trutas com a elevação do teor de fibra na dieta a até $15 \%$, com a utilização de celulose. As menores médias de ganho de peso e taxa de crescimento específico apresentada pelos peixes, a partir de $11 \%$ de fibra bruta na dieta, podem ter ocorrido em razão da redução na eficiência de absorção de nutrientes no intestino, causada pelos altos teores desse componente na dieta (Slavin, 2005), ou pela redução no consumo de ração nos maiores níveis de inclusão.

Os animais alimentados com dietas com 13 e 15\% de fibra bruta tiveram piores médias de conversão alimentar e menores taxas de eficiência proteica, em comparação aos demais teores que não diferiram entre si (Tabela 2). Esses resultados estão de acordo com a afirmação do National Research Council (1993), de que a utilização de altos teores de fibra bruta reduz o crescimento dos peixes. Anderson et al. (1984), no entanto, observaram que o aumento do nível de inclusão de celulose de $10 \mathrm{a}$ $40 \%$ na dieta de tilápias não alterou a taxa de eficiência proteica. Entretanto, Shiau et al. (1988) relataram que quando tilápias são alimentadas com 2, 6, 10 e 14\% de carboximetilcelulose, ocorre progressiva piora na conversão alimentar. Alguns autores observaram, no entanto, que a inclusão de 8,5 (Meurer et al., 2003) e 12\% (Lanna et al., 2004) de fibra bruta em dietas de tilápias não compromete a conversão alimentar dos peixes. Os resultados do presente trabalho mostram que teores de até $9 \%$ de fibra bruta são aceitáveis em dietas para juvenis de pacu, e não causam redução de seu crescimento.

A elevação do teor de fibra bruta da dieta afetou o conteúdo corporal de proteína (Tabela 3). Os peixes alimentados com 5\% de fibra bruta apresentaram os menores teores de proteína bruta na carcaça. A elevação do teor de fibra na dieta ocasionou aumento no teor de minerais na carcaça. Comportamento contrário foi observado na deposição de gordura corporal da carcaça (extrato etéreo), que apresentou redução com o aumento dos teores de fibra bruta da dieta. A diminuição do teor de gordura corporal pode ser atribuída à capacidade da fibra de diminuir a eficiência de absorção de gorduras no intestino delgado (Slavin, 2005).

Lanna et al. (2004) relataram que o aumento dos teores de fibra bruta da dieta não provocou alteração na composição da carcaça de alevinos de tilápias. Com menores teores de fibra bruta, os peixes tiveram elevação da deposição de gordura corporal. Segundo Slavin (2005), a redução no aporte de energia causado pela inclusão de fibras aumenta a oxidação e reduz a reserva de gorduras.

As concentrações de glicemia, triglicerideos e proteína total não foram alteradas com o aumento dos níveis de fibra bruta da dieta (Tabela 4). O emprego de teores crescentes de fibra na dieta de juvenis de pacu alterou seu metabolismo, com pequena elevação do colesterol plasmático, redução do teor de extrato etéreo da carcaça, maior síntese de proteína corporal e redução no aproveitamento das dietas, com sensível redução no desempenho quando se utilizaram taxas mais elevadas.

As mais altas concentrações de colesterol foram determinadas nos animais alimentados com $13 \mathrm{e}$ $15 \%$ de fibra bruta nas dietas. Thebaudin et al. (1997) propuseram que a absorção de sais biliares pela fibra resulta em alterações no metabolismo de gorduras, com diminuição de sua eficiência.

A redução no crescimento dos peixes com o aumento da fibra dietária também pode explicar a maior concentração de colesterol pela inclusão de maiores teores de fibra. O colesterol é formador de hormônios esteróis, responsáveis pelo crescimento do animal (Baldisserotto, 2002). Com a redução do

Tabela 3. Média \pm desvio-padrão da composição centesimal da carcaça de juvenis de pacu, alimentados com taxas crescentes de fibra bruta na dieta ${ }^{(1)}$.

\begin{tabular}{llll}
\hline Fibra bruta (\%) & Proteína bruta & Matéria mineral & Extrato etéreo \\
& $-------------------(\%)----------------$ \\
\hline 5 & $46,15 \pm 2,13 \mathrm{~b}$ & $10,78 \pm 2,56 \mathrm{~b}$ & $32,65 \pm 2,23 \mathrm{a}$ \\
7 & $48,83 \pm 1,20 \mathrm{ab}$ & $10,81 \pm 1,39 \mathrm{~b}$ & $31,91 \pm 3,83 \mathrm{a}$ \\
9 & $52,10 \pm 5,76 \mathrm{a}$ & $11,60 \pm 0,71 \mathrm{ab}$ & $31,30 \pm 3,53 \mathrm{a}$ \\
11 & $51,54 \pm 0,97 \mathrm{a}$ & $12,75 \pm 2,16 \mathrm{ab}$ & $29,59 \pm 1,77 \mathrm{ab}$ \\
13 & $51,72 \pm 2,88 \mathrm{a}$ & $13,48 \pm 0,38 \mathrm{a}$ & $26,21 \pm 2,29 \mathrm{bc}$ \\
15 & $52,63 \pm 3,05 \mathrm{a}$ & $13,25 \pm 1,02 \mathrm{a}$ & $24,71 \pm 1,19 \mathrm{c}$ \\
\hline $\mathrm{CV}(\%)$ & 6,14 & 12,98 & 8,98 \\
\hline
\end{tabular}

${ }^{(1)}$ Médias seguidas de letras iguais, nas colunas, não diferem entre si pelo teste de Duncan, a $5 \%$ de probabilidade. 
Tabela 4. Média \pm desvio-padrão de glicemia, colesterol, triglicerídeos e proteína total, em juvenis de pacu alimentados com taxas crescentes de fibra bruta ${ }^{(1)}$.

\begin{tabular}{|c|c|c|c|c|}
\hline $\begin{array}{c}\text { Fibra bruta } \\
(\%)\end{array}$ & Glicemia & $\begin{array}{c}\text { Colesterol } \\
-\left(\mathrm{mg} \mathrm{dL}^{-1}\right) \\
\end{array}$ & Triglicérides & $\begin{array}{l}\text { Proteína total } \\
\qquad\left(\mathrm{g} \mathrm{dL}^{-1}\right)\end{array}$ \\
\hline 5 & $69,74 \pm 5,41$ & $139,69 \pm 23,85 a^{(1)}$ & $315,88 \pm 114,53$ & $3,42 \pm 0,21$ \\
\hline 7 & $70,50 \pm 6,58$ & $156,42 \pm 9,99 \mathrm{ab}$ & $348,29 \pm 52,93$ & $3,60 \pm 0,17$ \\
\hline 9 & $65,33 \pm 6,31$ & $153,09 \pm 18,80 \mathrm{ab}$ & $337,61 \pm 35,47$ & $3,33 \pm 0,37$ \\
\hline 11 & $66,58 \pm 6,73$ & $155,37 \pm 19,28 \mathrm{ab}$ & $382,48 \pm 56,77$ & $3,48 \pm 0,19$ \\
\hline 13 & $64,65 \pm 10,03$ & $176,46 \pm 7,77 \mathrm{~b}$ & $362,15 \pm 56,69$ & $3,54 \pm 0,06$ \\
\hline 15 & $59,48 \pm 10,23$ & $169,14 \pm 10,99 b$ & $334,24 \pm 77,29$ & $3,52 \pm 0.20$ \\
\hline CV (\%) & 11,77 & 10,23 & 20,25 & 6,28 \\
\hline
\end{tabular}

${ }^{(1)}$ Médias seguidas de letras iguais, nas colunas, não diferem entre si pelo teste de Duncan, a 5\% de probabilidade.

crescimento, houve redução da formação de esteróis e, consequentemente, aumento da concentração de colesterol sanguíneo. Fibras solúveis, como pectina ou goma guar, têm efeito na redução de lipídeos, porém, fibras insolúveis, como farelo de trigo ou celulose, não têm esse efeito (Scheeman, 1986; Kritchevsky,1988; Thebaudin et al., 1997). A utilização de fibra insolúvel pode ser responsável pelo comportamento verificado no metabolismo de gorduras.

Hilton et al. (1983) não verificaram alterações na glicemia, quando trutas foram submetidas a dietas com teores crescentes de fibra. No presente estudo, o fato de a glicemia permanecer estável com o aumento da quantidade de fibra pode estar relacionado ao tipo de fibra utilizado, uma vez que a principal fonte de fibra foi insolúvel. As fibras insolúveis têm pouco efeito no metabolismo de açúcares (Thebaudin et al., 1997), enquanto fibras solúveis têm a capacidade de reduzir a glicemia e podem modificar a resposta da glicose plasmática após seu consumo (Kritchevsky, 1988).

\section{Conclusões}

1. A utilização de até $9 \%$ de fibra bruta em dietas para juvenis de pacu não afeta o desempenho produtivo, a composição corporal e os parâmetros plasmáticos.

2. Teores acima de $11 \%$ de fibra bruta prejudicam o desempenho animal, causam reduções de ganho de peso, nas taxas de crescimento específico e de eficiência proteica e aumento de conversão alimentar.

\section{Agradecimentos}

À Coordenação de Aperfeiçoamento de Pessoal de Nível Superior, por concessão de bolsa.

\section{Referências}

ABIMORAD, E.G.; CARNEIRO, D.J.; URBINATI, E.C. Growth and metabolism of pacu (Piaractus mesopotamicus Holmberg 1887) juveniles fed diets containing different protein, lipid and carbohydrate levels. Aquaculture Research, v.38, p.36-44, 2007.

ANDERSON, J.; JACKSON, A.J.; MATTY, A.J.; CAPPER, B.S. Effects of dietary carbohydrate and fibre on the tilapia Oreochromis niloticus (Linn). Aquaculture, v.37, p.303-314, 1984.

ANDRIGUETTO, J.M.; PERLY, L.; MINARDI, J.S.; SOUZA, G.A. de; BONA FILHO, A. Nutrição animal: as bases e os fundamentos da nutrição animal: os alimentos. 4.ed. São Paulo: Nobel, 2002. 395p.

BALDISSEROTTO, B. Fisiologia de peixes aplicada à piscicultura. Santa Maria: Universidade Federal de Santa Maria, 2002. 211p.

BIJLANI, R.L. Dietary fibre: consensus and controversy. Progress in Food and Nutrition Science, v.9, p.343-393, 1985.

DIOUNDICK, O.B.; STOM, D.I. Effects of dietary $\alpha$-cellulose levels on the juvenile tilapia Oreochromis mossambicus (Peters). Aquaculture, v.91, p.311-315, 1990.

FERNANDES, J.B.K.; CARNEIRO, D.J.; SAKOMURA, N.K. Fontes e níveis de proteína bruta em dietas para juvenis de pacu (Piaractus mesopotamicus). Revista Brasileira de Zootecnia, V.30, p.617-626, 2001.

GARCIA, J.R.E. Utilização da fibra bruta na nutrição da piracanjuba Brycon orbignyanus. 1998. 60p. Tese (Doutorado) - Universidade Estadual Paulista, Jaboticabal.

HANSEN, J.O.; STOREBAKKEN, T. Effects of dietary cellulose level on pellet quality and nutrient digestibilities in rainbow trout (Oncorhynchus mykiss). Aquaculture, v.272, p.458-465, 2007.

HILTON, J.W.; ATKINSON, J.L.; SLINGER, S.J. Effect of increased dietary fiber on the growth of rainbow trout Salmo gairdneri. Canadian Journal of Fisheries and Aquatic Science, v.40, p.81-85, 1983.

KNUDSEN, K.E.B. The nutricional significance of "dietary fibre" analysis. Animal Feed Science and Technology, v.90, p.3-20, 2001.

KRITCHEVSKY, D. Dietary fiber. Annual Reviews of Nutrition, v.8, p.303-328, 1988. 
LANNA, E.A.T.; PEZZATO, L.E.; FURUYA, W.M.; VICENTINI, C.A.; CECON, P.R.; BARROS, M.M. Fibra bruta e óleo em dietas práticas para alevinos de tilápias-do-Nilo (Oreochromis niloticus). Revista Brasileira de Zootecnia, v.33, p.2177-2185, 2004.

MEURER, F.; HAYASHI, C. ; BOSCOLO, W.R. Fibra bruta para alevinos de tilápia-do-nilo (Oreochromis niloticus, L.). Revista Brasileira de Zootecnia, v.32, p.256-261, 2003.

MONTAGNE, L.; PLUSKE, J.R.; HAMPSON, D.J. A review of interaction between dietary fibre and the mucosa, and their consequences on digestive health in young non-ruminant animals. Animal Feed Science and Technology, v.108, p.95-117, 2003.

NATIONAL RESEARCH COUNCIL. Nutrient requirements of warmwater fishes. Washington: National Academy Press, 1993. $122 p$

PEREIRA-FILHO, M.; CASTAGNOLLI, N.; KRONKA, S.N. Efeito de diferentes níveis de proteína e de fibra bruta na alimentação de juvenis de matrinxã, Brycon cephalus. Acta Amazonica, v.24, p.1-8, 1994.

SAS INSTITUTE. Statistical analysis system. Version 9.1. Cary: SAS Institute, 2006.
SCHEEMAN, B.O. Dietary fiber: physical and chemical properties, methods of analysis, and physiological effects. Food Technology, v.40, p.104-110, 1986.

SHIAU, S.-Y.; YU, H.-L.; HWA, S.; CHEN, S.-Y.; HSU, S.-I. The influence of carboxymethylcellulose on growth, digestion, gastric emptying time and body composition of tilapia. Aquaculture, v.70, p.345-354, 1988.

SILVA, D.J.; QUEIROZ, A.C. de. Análise de alimentos: métodos químicos e biológicos. 3.ed. Viçosa: UFV, 2006. 235p.

SLAVIN, J.L. Dietary fiber and body weight. Nutrition, v.21, p.411-418, 2005.

THEBAUDIN, J.Y.; LEFEBVRE, A.C.; HARRINGTON, M.; BOURGEOIS, C.M. Dietary fibres: nutritional and technological interest. Trends in Food Science \& Technology, v.8, p.41-48, 1997.

URBINATI, E.C.; GONÇALVES, F.D. Pacu (Piaractus mesopotamicus). In: BALDISSEROTO, B.; GOMES, L.C. (Ed.). Espécies nativas para piscicultura no Brasil. Santa Maria: Universidade Federal de Santa Maria, 2005. p.225-256.

WENK, C. The role of dietary fibre in the digestive physiology of the pig. Animal Feed Science and Technology, v.90, p.21-33, 2001.

Recebido em 25 de maio de 2010 e aprovado em 20 de julho de 2010 